\title{
Approaches for Estimating the Supply of Ecosystem Services: Concepts for Ecosystem-Based Management in Coastal and Marine Environments
}

\author{
Fiona E. Culhane, Leonie A. Robinson, and Ana I. Lillebø
}

\begin{abstract}
Ecosystem services have emerged as a critical concept for EcosystemBased Management (EBM) in aquatic environments, namely in coastal and marine environments. However, despite conceptual advances over the last two decades, major challenges remain in the operationalisation of ecosystem service concepts and practical application. This chapter describes a selection of EBM assessment approaches applied to coastal and marine environments, where the ecosystem services approach is key. These approaches range from qualitative to quantitative, all being transdisciplinary. In the first, (ODEMM project, supported by linkage frameworks) trade-offs in EBM management options can be considered, in terms of their potential to reduce ecological risk, maintain sustainable supply of ecosystem services, and the governance complexity associated with implementing them. In the second, (AQUACROSS project, combining causality links relations and spatial multicriteria analysis) trade-offs are supported by maps with governance boundaries, spatially explicit valuation of ecosystem services and ecological risk. In the third, (MCES project, supported by the GIS-based modelling tool InVest) trade-offs are supported by a developed spatially explicit proxy for the habitats' vulnerability to deliver ecosystem services. Finally, we describe a policy-based operational assessment tool that allows users to assess the current and future capacity of regional seas to supply ecosystem services, based on their current and future ecosystem status reporting. We go on to describe some lessons learnt from our experience in applying these approaches.
\end{abstract}

F. E. Culhane $(\bowtie) \cdot$ L. A. Robinson

School of Environmental Sciences, University of Liverpool, Liverpool, UK

e-mail: F.Culhane@liverpool.ac.uk; Leonie.Robinson@liverpool.ac.uk

A. I. Lilleb $\varnothing$

Department of Biology \& CESAM, Campus Universitário de Santiago, University of Aveiro, Aveiro, Portugal

e-mail: lillebo@ua.pt

(C) The Author(s) 2020

T. G. O'Higgins et al. (eds.), Ecosystem-Based Management, Ecosystem Services and Aquatic Biodiversity, https://doi.org/10.1007/978-3-030-45843-0_6 


\section{Lessons Learned}

- For marine ecosystems, data availability is often a barrier to operationalising the ecosystem service concept. Ideally, spatial data would be available and, in many cases, it is becoming so. However, assessments are needed now. We show that there is existing information that can be applied to ecosystem service assessments for marine environments, and this should not be a barrier to carrying out assessments now.

- Consider all the ways that nature contributes to human wellbeing. There are criticisms of some approaches to ecosystem service classifications and assessments, because the services cannot be clearly linked to market values and economic assessments. This narrows our perspective on the breadth of ecosystem services. We show that by carrying out a supply side assessment, all the ways that nature contributes to wellbeing can be considered. This can be seen as complementary to demand side assessments and as an end-point in itself. Economic valuation does not need to be the only end point.

\section{Needs to Advance EBM}

- Scientists and policy makers need to be open to draw on different approaches including expert judgement and stakeholder knowledge, policy information, as well as, detailed habitat mapping or spatially explicit modelling techniques. These can then be used, together or in isolation, to show how ecosystem integrity can affect human well-being, fulfilling the critical need for balanced (economic, ecological, social) management actions to be taken.

\section{Introduction}

The concept of nature benefits for humans, is not new, however, it was first in 1983, almost forty years ago, that Ehrlich and Mooney used the term 'Ecosystem Services' in an International Scientific Indexing (ISI) journal (see Flood et al. (2020) for a discussion of earlier development of the concept). Under the title 'Extinction, Substitution, and Ecosystem Services' and using different biomes, authors showcased the need for a "conservative approach to the maintenance of services through minimizing anthropogenic extinctions" (Ehrlich and Mooney 1983). Regarding the marine biome, the biggest biome in the world, and the accompanying ecosystems services, authors highlighted the impact of fisheries over fish stocks and the role of economy as a driver for extinction and for substitution of target species. Their recommendations followed the need for a "careful preservation of ecosystems and thus of the populations and species that function within them". Since then the concept of 'Ecosystem Services' has evolved in order to become effectively operationalised, but major challenges still remain, namely, how to decide who will win and who will lose, as trade-offs are inherent to the decision making process. This is of paramount importance in the context of global socio-ecological challenges and 
sustainable development strategies for coastal and marine environments. Such challenges include human indirect drivers like sea level rise, extreme weather events (e.g. floods and storm surges) and invasive species, and human direct drivers (e.g. economic activities). Global strategies tackling these challenges include those based around Blue Growth, Biodiversity and Climate Change. Ecosystem-Based Management (EBM) acknowledges that human well-being and ecological status are linked and integrates multiple drivers and pressures into adaptive management plans (UNEP 2011). In this context, ecosystem services have emerged as a critical concept to operationalise EBM.

\subsection{Ecosystem Services Concept}

Ecosystem services have been defined in different ways over the years, with the term services often being used interchangeably to mean "the benefits people obtain from ecosystems" (MA 2005), to the ecosystem structures, processes or functions that generate the services. More recently, the ecosystem service cascade model has been widely adopted to clearly delineate where a service sits in relation to what generates it (in the ecosystem), and what benefits people get from it (in the socio-economic system) (Potschin and Haines-Young 2011). Following the rationale of the ecosystem services 'cascade' model and Culhane et al. (2019a), we define ecosystem services here as:

Ecosystem services represent the flow of ecosystem capital that is realised because of a human active or passive demand (modified from EEA (2015)). They are thus the final outputs from ecosystems that are directly consumed, used (actively or passively) or enjoyed by people. (Fisher et al. 2009; Haines-Young and Potschin 2013; Maes et al. 2013)

Examples of coastal and marine ecosystem services include nutrition from fish and shellfish, flood and coastal protection from saltmarsh habitats, and artistic inspiration from seascapes and marine animals (Culhane et al. 2019a, and see Fig. 1 for further examples). In order to recognise all the services that ecosystems and marine environments supply, typologies of services have been developed. These categorise services and make their assessment operational. Early international initiatives to develop typologies classified services under four broad categories: provisioning (such as food from fish); regulation and maintenance (such as waste regulation); supporting (such as primary production); and cultural services (such as marine species to observe or to research) (MA 2005; TEEB 2010). The concept of Final Goods and Ecosystem Services (FEGS) also developed (see DeWitt et al. (2020) for a summary of this). These are a subset of ecosystem services, generally not including the supporting services, that can be directly linked to a beneficiary, thus avoiding double-counting when assigning a monetary or market value. Following these, ecosystem service typologies have been further developed and/or adapted for the marine environment (e.g. Böhnke-Henrichs et al. 2013), see Fig. 1 for some examples from this typology, which retains supporting services). CICES, the Common International Classification of Ecosystem Services (Haines-Young and Potschin 


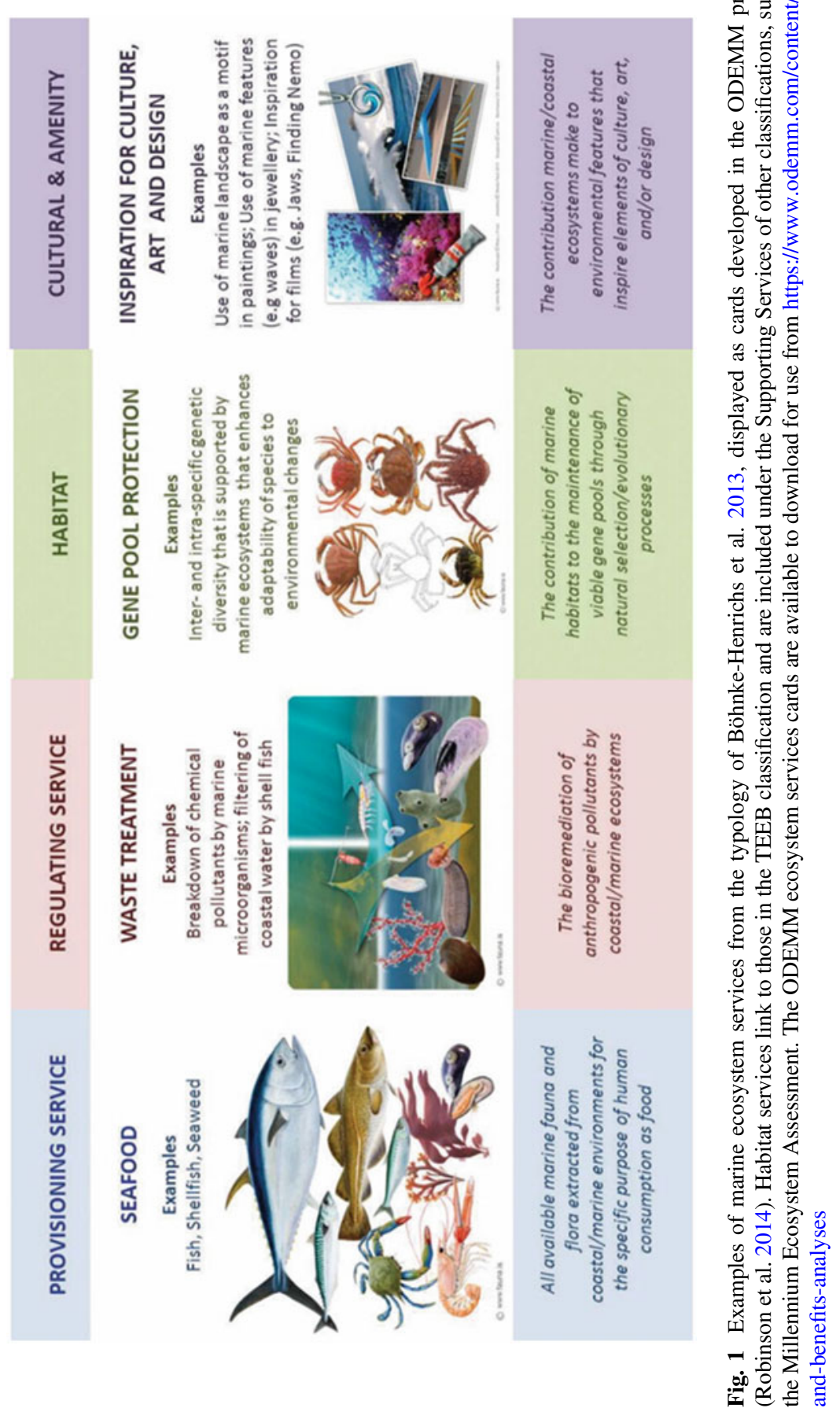


2013) is the reference typology for the European Union's assessments linked to the Biodiversity Strategy (EC 2011). It is a hierarchical typology that recognises three categories of ecosystem services: provisioning, regulation and maintenance, and cultural services at the broadest level and further subdivides these categories into more specific services at lower levels (see Flood et al. (2020) for further discussion of ecosystem service classification systems). CICES includes only 'final' services, though one criticism of the typology is that some of the included services are, in fact, supporting (or intermediate). CICES was developed primarily for terrestrial environments but has been adapted for the marine environment (Culhane et al. 2019a), and should be applicable across biomes allowing a Europe wide assessment.

\subsection{Policy Background}

Around twenty years ago, Costanza and colleagues estimated the value of the world's Ecosystem Services and natural capital, showing that coastal (tidal marsh and mangroves) and marine (open ocean, shelf, estuaries, seagrasses) services accounted for circa $68 \%$ of the global value for ecosystem services (Costanza et al. 1997). Just after, in the year 2000, the Millennium Ecosystem Assessment was called for by the United Nations Secretary-General Kofi Annan, as part of the 'The Role of the United Nations in the 21st Century'. Regarding ecosystems, the objective was "to assess the consequences of ecosystem change for human well-being and to establish the scientific basis for actions needed to enhance the conservation and sustainable use of ecosystems and their contributions to human well-being" (MA 2005).

Then ten years ago, the global initiative 'The Economics of Ecosystems and Biodiversity (TEEB)' focused on 'making nature's values visible' in order to mainstream the values of biodiversity and Ecosystem Services into decision-making at all levels (TEEB 2010). Within TEEB special attention is given to 'blue growth' and human dependence on healthy ocean ecosystems and on coastal and marine biodiversity. About the same time, the European Union (EU) Biodiversity Strategy for 2020 aimed to halt the loss of biodiversity and Ecosystem Services, reflecting the commitments taken in 2010 within the International Convention on Biological Diversity. As part of the strategy, working groups for mapping and assessment of ecosystem services, including a marine pilot, provided supporting guidance for EU member states (Maes et al. 2016). Just after, in 2012, an independent intergovernmental body of the United Nations 'The Intergovernmental Science-Policy Platform on Biodiversity and Ecosystem Services (IPBES)' was established 'to strengthen knowledge foundations for better policy through science, for the conservation and sustainable use of biodiversity, long-term human well-being and sustainable development'. This platform stands for nature and biodiversity, in the same way that the 'Intergovernmental Panel on Climate Change (IPCC)' provides the latest sciencebased assessments related to climate change, including possible response options. 
In the last five years, different but complementary initiatives have taken place acknowledging the need for global actions towards unprecedented changes in nature, climate and human population growth. In 2015, the United Nations, together with governments, businesses and civil society, agreed on the Sustainable Development Agenda for 2030 that integrates seventeen interlinked Sustainable Development Goals (SDG's). Although, SDGs should not be addressed individually, SDG 14 is devoted to 'Conserve and sustainably use the oceans, seas and marine resources for sustainable development'. In the same year the 'Paris Agreement on climate change' entered into force, being essential for the achievement of the SDGs. The former initiatives, TEEB, IPBES, as well as the EU Strategy for biodiversity beyond 2020 are also framed in the scope of the SDGs.

In this context, Ecosystem-Based Management (EBM), a holistic approach that aims to balance the multiple interrelated dimensions of ecological integrity and human well-being, appears a useful framework to operationalise the concept of ecosystem services (Gómez et al. 2016, 2017). Likewise, one can argue that achieving EBM might be more attainable where the ecosystem services approach is included, since it enables stakeholders and decision makers to see a tangible way in which the integrity of ecosystems directly (actively or passively) affects the wellbeing of humans. To this end this chapter aims at showcasing selected EBM assessment approaches applied to coastal and marine environments that incorporate understanding and assessment of ecosystem services and to draw lessons learnt from our experience.

\section{Operationalising Ecosystem Services in EBM}

\subsection{Ecosystem Services and Trade-Offs in EBM Management Options}

Different decision support tools can support trade-off options regarding the provisioning of ecosystem services. These can be supported by linkage frameworks (e.g., see Robinson and Culhane 2020), by causality links relations (e.g., AquaLinksTool, Nogueira 2018), by spatially-explicit GIS-based modelling tools (e.g., Willaert et al. 2019) or by a combination of the above mentioned decision support tools (e.g., see Lillebø et al. 2020). Three selected examples are now presented.

\subsubsection{ODEMM Project: https://www.odemm.com}

In the ODEMM project a typology of marine ecosystem services was developed (Böhnke-Henrichs et al. 2013) and an assessment undertaken whereby stakeholders compared management options based on three major criteria: ecological risk, ecosystem service supply and governance complexity (Robinson et al. 2014: Chap. 7). 
As illustrated in Fig. 2, management options could be applied to reduce impacts through a number of different pathways, and the reduction in risk to ecological components was considered in terms of any resultant change in the supply of ecosystem services (a framework that aligns with the DPSIR, and later DAPSI(W) R(M) concepts, see Elliott and O'Higgins (2020)). This was considered against the complexity of governance required to implement the compared management options, and the effect of ecological risk reduction on potential achievement of ecological goals as set out by the Marine Strategy Framework Directive.

It was not always the case that management options delivered benefits in terms of all three criteria considered in the same way (Fig. 3). In terms of the examples explored, stakeholders generally found that the management option that delivered the best reduction in risk to achievement of the MSFD good environmental status objectives, was also least complex in terms of governance required to instigate it, but was not the most promising in terms of the benefits to sustainable supply of services. This helps to illustrate the trade-offs experienced in EBM. Participants involved in the ODEMM trade off exercises found the approach to be very useful in terms of helping to visualise "how the sea works", providing a "practical approach to link management options with potential changes in the provision of ecosystem services" (ODEMM Deliverable 19).

\subsubsection{AQUACROSS Project: https://aquacross.eu}

The EBM approach (see Piet et al. 2020) was applied to the Vouga river coastal watershed, along a continuum of freshwater to marine habitats under the classification of the Natura 2000 network (Lillebø et al. 2018). This case study also aimed to showcase causality links in a linkage chain relating activities, pressures and habitats/ highly mobile biotic groups and ecosystem services (Teixeira et al. 2018, 2019; Culhane et al. 2019b) and to assess the vulnerability of ecosystem components regarding the provisioning of ecosystem services (Lillebø et al. 2018).

In this social-ecological system and as part of the EBM framework, stakeholders were invited to value ecosystem services through a spatial multi-criteria analysis that took place at two different spatial scales (Lillebø et al. 2019; Martínez-López et al. 2019). From the resulting prioritization maps representing stakeholder's perceptions and beliefs regarding ecosystem services, valuations were generated and supported the discussion of the areas for potential interventions (ecosystems restoration) and associated trade-offs. As part of the EBM trans-disciplinary approach, stakeholders were also invited to express their concerns regarding the foreseen management options. Simultaneously, causality links and risk assessment were undertaken though a tool that establishes a linkage chain relating activities, pressures and habitats/highly mobile biotic groups and ecosystem services, to assess the vulnerability of ecosystem components regarding the provisioning of ecosystem services (AquaLinksTool, Nogueira (2018)) as shown in Fig. 4. The full linkage matrices dataset is freely available for download https://zenodo.org/record/1101159\#. XbKsfS3MyqA. 


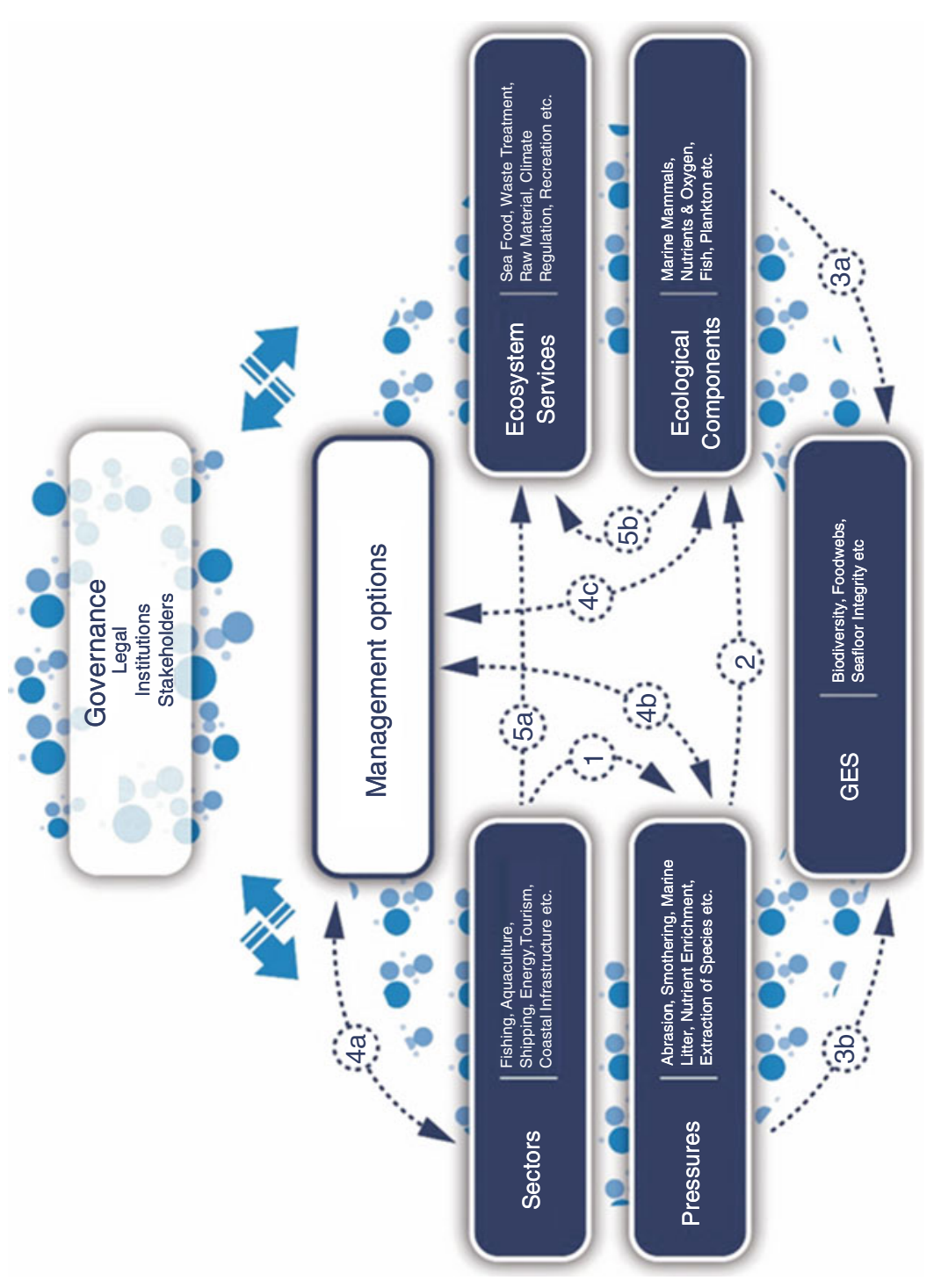

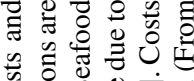

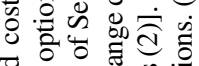

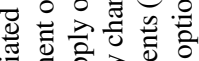

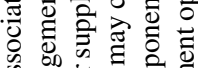

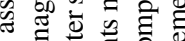

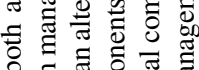

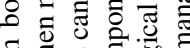

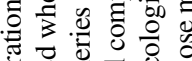

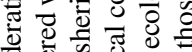
ज的荡 융 흥 융

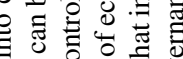
o क 0 ن

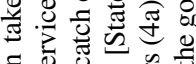
สี น 0

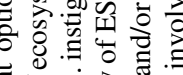

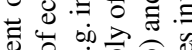

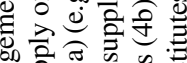

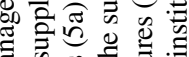
ज्ञ

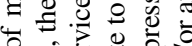

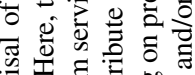

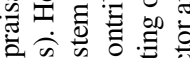

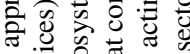

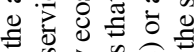

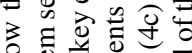

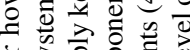
पै

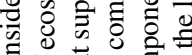

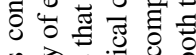
诺

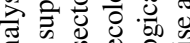
ह \& 4 응

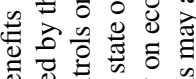

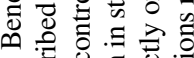

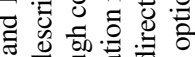

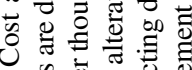
$\checkmark \stackrel{0}{0}$ 过

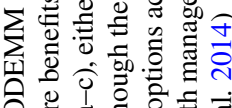

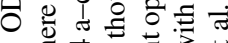
过式范芯

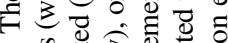

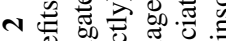

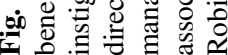


Fig. 3 A final outcome table following completion of all three exercises, where numbers represent the order in which the Management Options (MO A, B, C) work best, in terms of outcomes for the different criteria considered

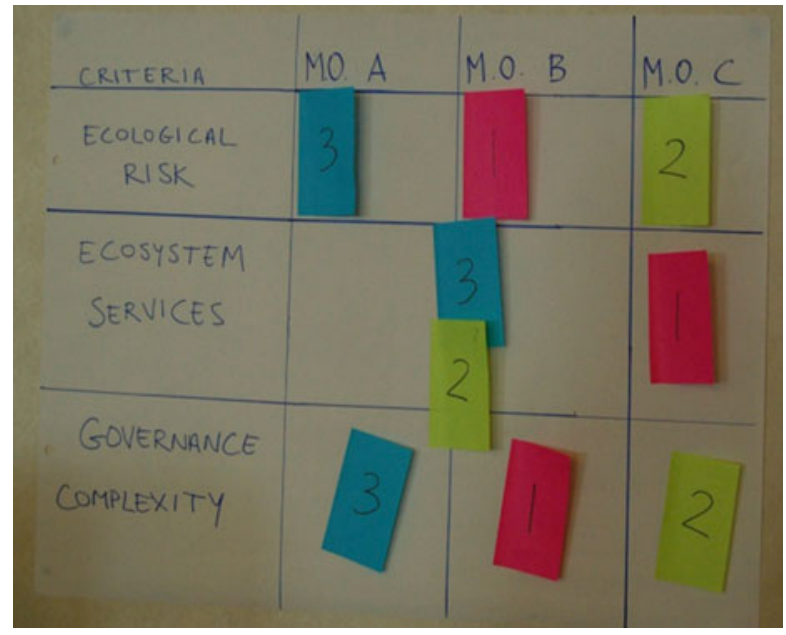

The vulnerable habitats selected through the AquaLinksTool clearly matched stakeholders' concerns, as well as their ecosystem services prioritization maps (Lillebø et al. 2019; Martínez-López et al. 2019). The combined approach contributed to the effectiveness (hitting the environmental target), the efficiency (making the most for human wellbeing), and to equity and fairness (sharing the benefits) of the proposed EBM responses. Lillebø et al. (2020) detail the co-development process of an EBM plan foreseen to mitigate unintended impacts on biodiversity in Vouga estuary and to its end support the development of the Vouga estuary management plan.

\subsubsection{MCES Project}

In the MCES project, a vulnerability index of the potential of marine and coastal habitats to deliver ecosystem services was developed. This is an example of an approach to implement ecosystem service assessments in EBM using spatially explicit modelling tools, i.e., by generating maps, GIS-based models enable decision makers to assess quantified trade-offs associated with alternative management options and to identify areas where these can take place. Relevant examples of open source models are ARIES-Artificial Intelligence for Ecosystem Services, already applied for machine learning for ecosystem services (Willcock et al. 2018); MARXAN with Zones enabling to 'develop multiple-use zoning plans for natural resource management' (Watts et al. 2009; Jumin et al. 2018) and InVestIntegrated Valuation of Ecosystem Services and Trade-offs, already used for calculating vulnerability of marine habitats to deliver ecosystem services (Willaert et al. 2019; Cabral et al. 2015). For detailed consideration of EBM modelling tools see Fulford et al. (2020) and Lewis et al. (2020). 


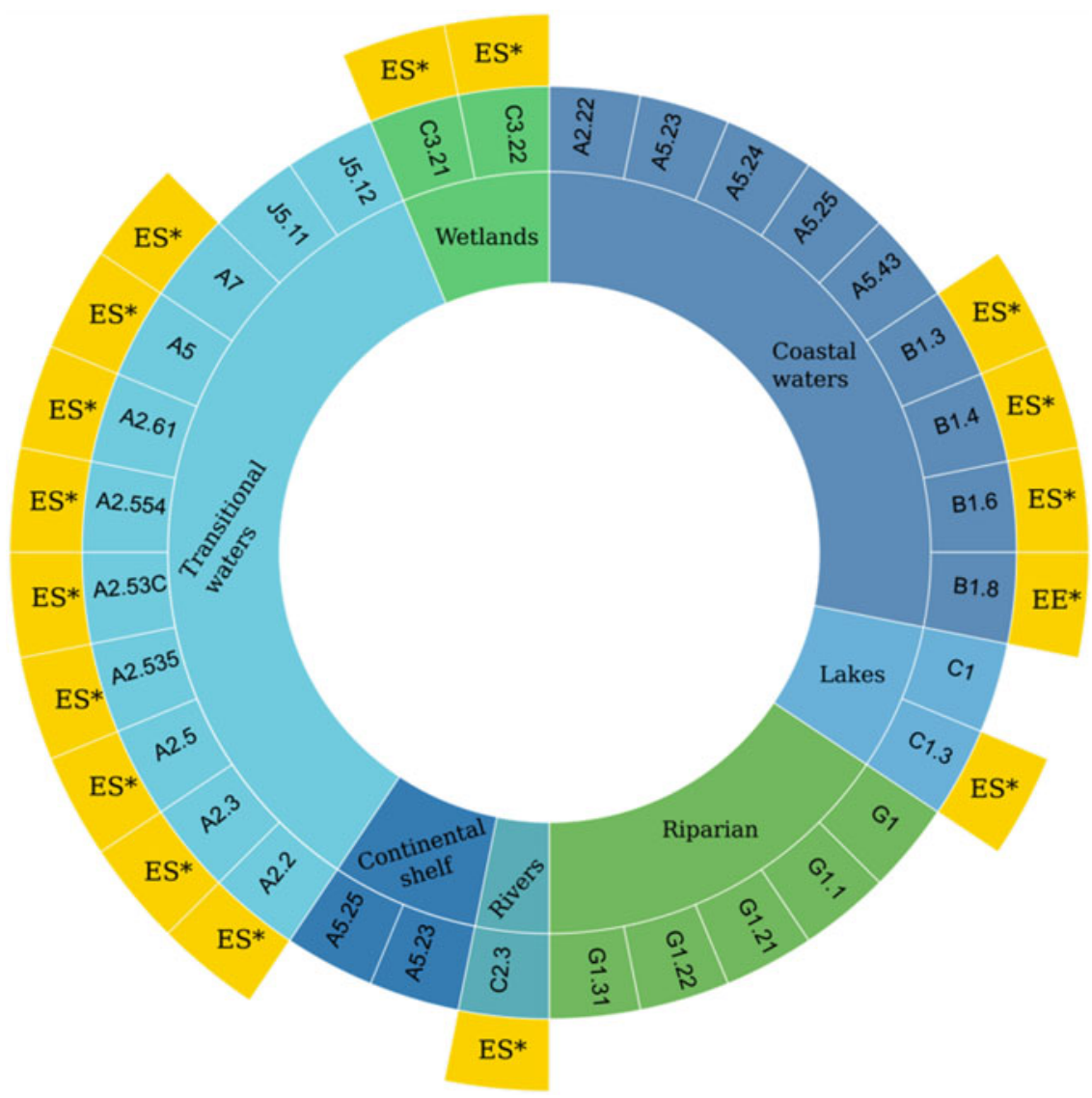

Fig. 4 Vulnerability (ES*) of the Vouga river coastal watershed habitats under classification of Natura 2000 network to provide ecosystem services defined with AquaLinksTool. (Image source: Adapted from Lillebø et al. (2018), plotted with Mauri et al. (2017)). EUNIS habitats codes: A5.23 Infralittoral fine sand; A5.25 Circalittoral fine sand; A2.22 Barren or amphipod-dominated mobile sand shores; A5.23 Infralittoral fine sand; A5.24 Infralittoral muddy sand; A5.25 Circalittoral fine sand; A5.43 Infralittoral mixed sediments; B1.3 Shifting coastal dunes; B1.4 Coastal stable dune grassland (grey dunes); B1.6 Coastal dune scrub; B1.8 Moist and wet dune slacks; A2.2 Littoral sand and muddy sand; A2.3 Littoral mud; A2.5 Coastal saltmarshes and saline reedbeds; A2.535 Juncus maritimus mid-upper saltmarshes; A2.53C Marine saline beds of Phragmites australis; A2.554 Flat-leaved Spartina swards; A2.61 Seagrass beds on littoral sediments; A5 Sublittoral sediment; A7 Pelagic water column; J5.11 Saline and brackish industrial lagoons and canals; J5.12 Saltworks; C1 Surface standing waters; C1.3 Permanent eutrophic lakes ponds and pools; C3.21 Common reed (Phragmites) beds; C3.22 Common clubrush (Scirpus) beds; C2.3 Permanent non-tidal smooth flowing watercourses; G1 Broadleaved deciduous woodland; G1.1 Riparian and gallery woodland (Alnus Betula Populus or Salix); G1.21 Riverine Fraxinus-Alnus woodland; G1.22 Mixed Quercus-Ulmus-Fraxinus woodland of great rivers; G1.31 Mediterranean riparian Populus forests) 


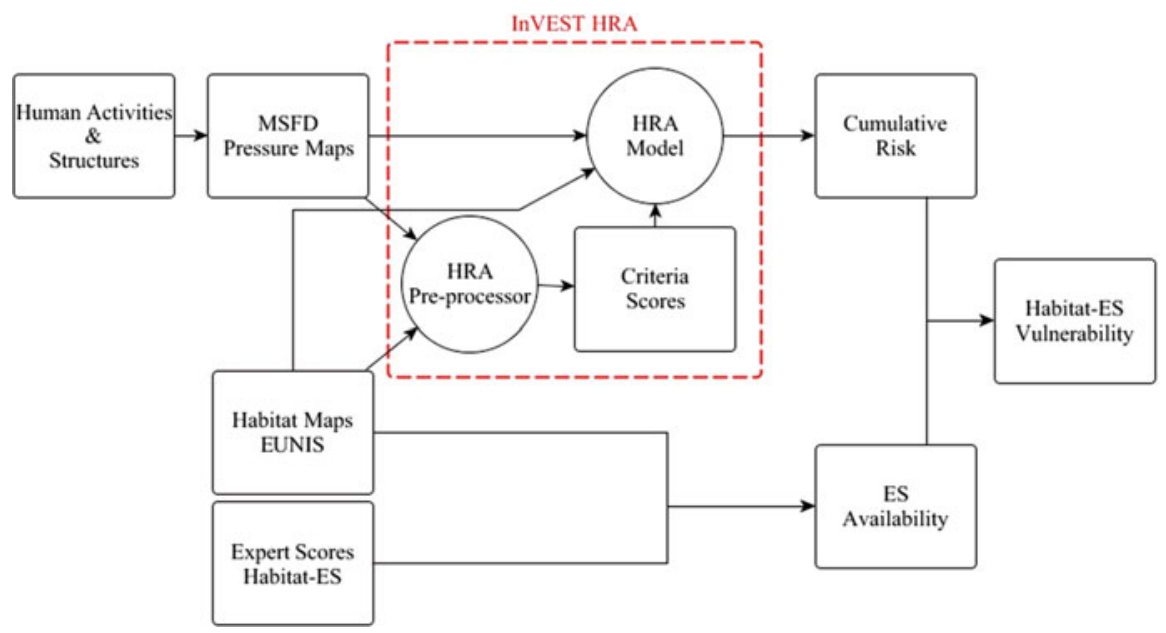

Fig. 5 Schematic representation of the workflow to assess the vulnerability of marine and coastal habitats' potential to deliver ecosystem services. (Image source: Willaert et al. 2019. Note: MSFD-Marine Strategy Framework Directive; HRA—InVEST Habitat Risk Assessment tool; ES-Ecosystem Services; EUNIS—habitat classification system)

The MCES project example showcases a vulnerability-based approach to capture Ecosystem Services in EBM. To this end, the considered approach combined the InVEST habitat risk assessment tool with the identified ecosystem services to create a proxy for the habitats' vulnerability to deliver ecosystem services in support of coastal and marine EBM. Figure 5 illustrates the framework combining the supply and demand for coastal and marine ecosystem services followed by Willaert et al. (2019). The case study was the western-Atlantic coast of Portugal that included the Nazaré Canyon (> $3000 \mathrm{~m}$ depth within the study region), Óbidos Lagoon (transitional waters), São Martinho do Porto bay (marine inlet), and Berlengas Archipelago (UNESCO world biosphere reserve).

As concluded by Willaert et al. (2019) "The mapping of benthic habitats has opened new avenues, contributing to improve not only marine spatial plans, but also the EBM approach by facilitating the combination of spatial explicit GIS tools with supply and demand of marine ES, human activities and their related impacts, as well as with other natural impacts (e.g. climate change) to forecast scenarios (including marine ES trade-offs) and to open the floor to discussion (namely in stakeholders participatory processes) and to sustainable decision making processes in a 'Blue Growth' context by maximizing the net benefits provided by marine environments over time".

The diversity of habitats in the selected area, the proposed approach to capture vulnerability, and the generated maps (EBM base line and EBM management options prospective scenarios) showcase maritime spatial planning and 'Blue Growth' in the context of the SDGs for 2030. 


\section{A Policy-Based Regional Seas Assessment of the Capacity to Supply Ecosystem Services}

In this section we describe an assessment approach (MECSA: Marine ecosystem capacity for service supply assessment) developed with the European Environment Agency that utilises policy-reported ecosystem status information (from the Marine Strategy Framework Directive and other relevant reporting) to assess current and future capacity to supply ecosystem services (Culhane et al. 2020; Culhane et al 2019a). The key steps and the types of output that can be generated are summarised.

\subsection{Using Ecosystem State Information in Ecosystem Service Assessments}

The state of the ecosystem can tell us something about the capacity of the ecosystem to supply services, and this is the underlying assumption of this assessment approach. Across multiple services it can be assumed that good ecosystem state underpins good capacity for service supply, since the ecosystem service supply relies on the integrity of the ecosystem (Burkhard et al. 2012; Culhane et al. 2019b). However, at an individual service level, this is not necessarily the case, and we cannot assume that good ecosystem state will necessarily equate to good ecosystem services supply. Thus, the second underlying assumption of this assessment is that we understand something about the ecosystem state-service supply relationship, and we can use this to interpret state information in relation to what it means for the supply of services (Box 1).

\section{Box 1 Understanding the State-Service Relationship}

Different services will have different types of relationship with the state of the parts of the ecosystem that supplies them.

Examples:

- Flood protection capacity is better in the presence of a greater area of saltmarsh habitat (King and Lester 1995).

- Heavily-grazed seagrass beds, even though in worse state than ungrazed areas, still support up to three times more coastal protection through their root system that unvegetated areas (Christianen et al. 2013).

- Macroalgae habitat quality is more important than habitat area for service supply e.g. for maintaining fish habitat (van Lier et al. 2018).

It is important to understand this relationship in order to use state information to truly represent the capacity of the ecosystem to supply services. Different services rely on different aspects of the ecosystem. These need to be identified. 


\subsection{Steps to Implementing the Method}

This approach entails three main steps, all set in the context of understanding the state-service relationship (Box 1).

- Firstly, the parts of the ecosystem that supply the service being assessed are identified. We described an approach to identify service providing units (SPUs) (see linkage framework chapter and Culhane et al. 2018). The relative contribution of these SPUs can be determined, and only the critical ones of these taken forward for a full assessment.

- The second step involves determining the relative contribution of SPUs to the service supply and identifying which are critical.

- In the third step, the specific state service relationship for the critical SPUs is described and the most appropriate indicators of these identified. State information is then used to fulfil these indicators, though in practice, this is often determined by what is available rather than what is most appropriate. This is interpreted in relation to ecosystem service supply capacity, using understanding of the state-service relationship.

\subsection{Example Case Study: North East Atlantic}

The three steps of the method are illustrated through an example of a cultural ecosystem service-recreation and leisure from whale watching in the North East Atlantic.

As well as whale watching occurring from the shore and other non-commercial routes, it is a growing enterprise in many regions (e.g. Elejabeitia et al. 2012; IUCNACCOBAMS 2016), often representing important economic benefits to rural communities (Ryan et al. 2018). In the North East Atlantic, commercial whale watching tours operate around the shores of Ireland, Scotland, England, Portugal and Northern Spain. In the first step of identifying the SPUs, we define these for this service as the whales that are watched by people, and the habitats that support those whale populations. Since whales are highly mobile and may make use of many habitats, we focus here on the whales themselves, as their populations are likely to reflect the condition of their habitats. We identified the relevant SPUs by checking whale tour operator websites and the species advertised as being seen on tours (Table 1).

To identify the critical SPUs for step two, we consider whether some species are more important than others. We find that, while common species are more reliably seen, rare species may constitute a special and equally important experience. Thus, in this case, we take all species forward as being critical. We define the state-service relationship as being that a greater whale population will result in a greater likelihood of seeing whales. Thus, in this case, good ecosystem state of whale populations 
Table 1 Summary of results for the current state and direction of change of the metrics relevant to assess the 'whale watching' service in the North East Atlantic

\begin{tabular}{l|l|l|l}
\hline Indicator & Classification & $\begin{array}{l}\text { \% Whale species } \\
\text { assigned }\end{array}$ & $\begin{array}{l}\text { Service supply } \\
\text { capacity }\end{array}$ \\
\hline \multirow{2}{*}{ State } & Pass & 56 & Good \\
\cline { 2 - 3 } & Fail & 17 & \\
\cline { 2 - 3 } & $\begin{array}{l}\text { Insufficient } \\
\text { information }\end{array}$ & 28 & \\
\hline \multirow{2}{*}{$\begin{array}{l}\text { Direction of } \\
\text { change }\end{array}$} & Increasing & 22 & \\
\cline { 2 - 3 } & Stable & 0 & \\
\cline { 2 - 3 } & Decreasing & 0 & \\
\cline { 2 - 3 } & $\begin{array}{l}\text { Insufficient } \\
\text { information }\end{array}$ & 78 & \\
\hline
\end{tabular}

would correspond with a good capacity for the supply of this service. We can then look to policy assessments to find information on the status of each of these whale populations in the North East Atlantic.

To interpret this state information in relationship to the service supply capacity, we go back to our state-service relationship, where we had determined that more whales would lead to greater likelihood of spotting whales, and that each whale species is as important as any other. Therefore, we assess what is happening overall to whale populations in the North East Atlantic. From the policy status assessments, we see that most $(56 \%)$ are in a good state, passing their policy objectives, but there is insufficient information about the direction of change of their populations (Fig. 6). Thus, the overall capacity for the ecosystem to supply this service is good but we do not know how this is changing.

\subsection{Conclusions}

This assessment approach uses available ecosystem state information to assess the capacity of the ecosystem to supply services. In doing so, a number of assumptions need to be made that relate to understanding the state-service relationship, and to the suitability of the state information available. In this example, we could assess the current capacity of the service but we could not assess the direction of change. While policy information allows a source of status assessments that can be used for this purpose, there are many unknowns and uncertainties. Nevertheless, this approach allows for assessments at broad regional scales, using existing information where it exists and does not rely on the availability of spatial or other data that may not be available.

It is also important to note that, although this service was found to have a good capacity overall, not every species is meeting its ecological objectives. There is still a 


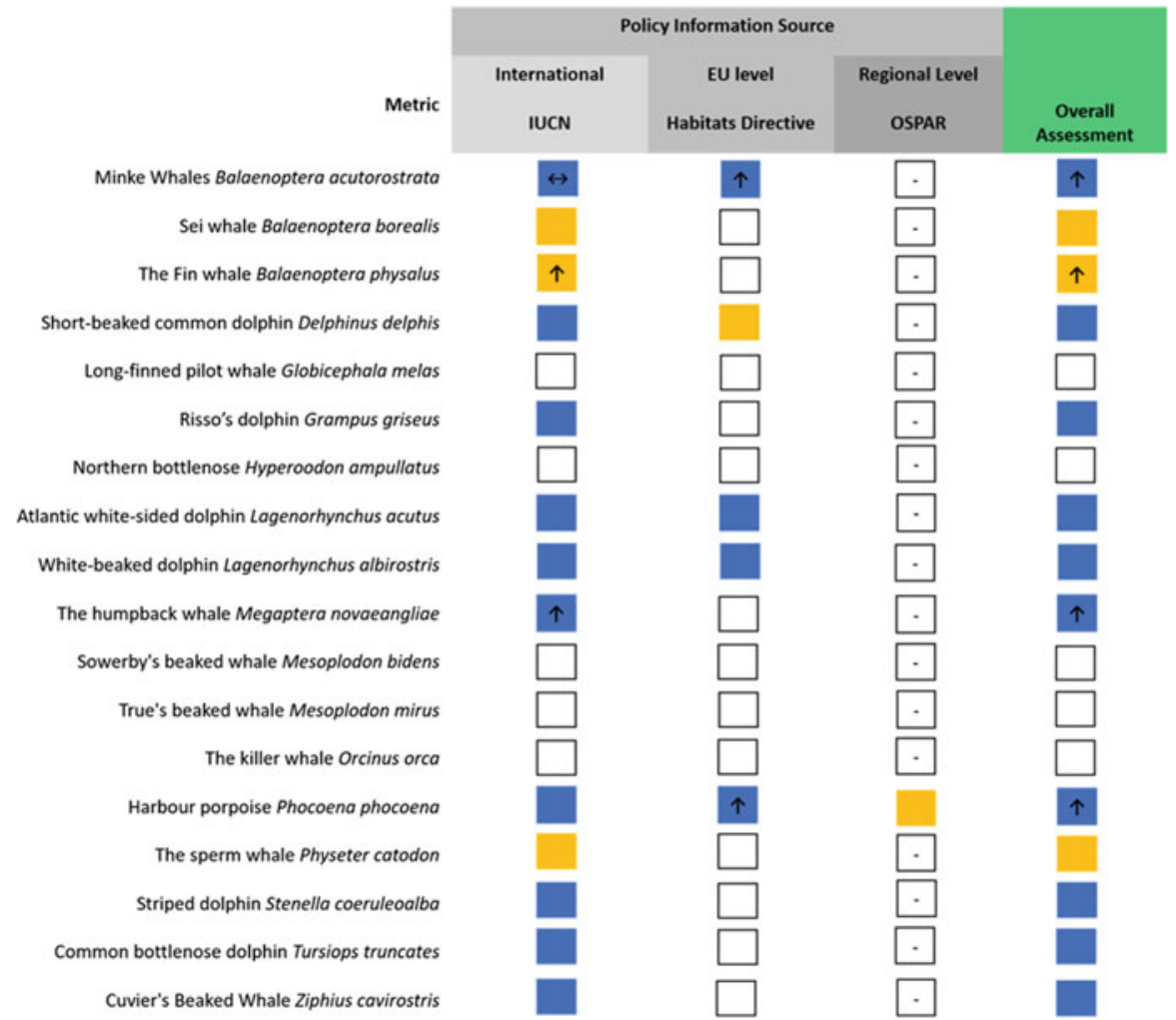

Fig. 6 List of commonly, occasionally or rarely spotted cetacean species advertised by whale watch tour operators (nine tour operators consulted from Ireland, Scotland, England, Portugal and Northern Spain) in the North East Atlantic region. The state of each whale species metric reported under each policy for the North East Atlantic is given. Legend: blue box = policy objectives achieved (here meaning that the whale population is in a good state); yellow box $=$ fail to meet policy objectives; white box = unknown state/no assessment could be made; upward/downward arrow $=$ Trend towards/away from achieving policy objectives; arrow on both sides $=$ no trend; no arrow $=$ unknown trend, 'Minus' symbol means the metric is not relevant for a particular policy)

need for conservation measures to protect species, and an ecosystem service assessment does not replace a biodiversity assessment.

\section{Lessons Learnt and Next Steps}

We draw a number of conclusions and lessons from our experience in trying to make the ecosystem services concept operational in Ecosystem-Based Management (adapted from Culhane et al 2019a). 


\subsection{Lessons Learnt}

1. Make use of what is currently available

Approaches supported by spatially explicit data (AQUACROSS, MCES) described above, can make use of detailed spatial data on habitats, ecosystem service supply and demand. However, for marine environments, spatial data is often scarce, in particular at the large spatial scales that may be relevant for policy assessments. Alternatively, the other approaches that we demonstrated (MECSA, ODEMM) show that it is still possible to carry out assessments of marine ecosystem services using what is available. Although these assessments may not be ideal in terms of the information underpinning them, they can form a baseline and indicate where there are potential problems in sustainability, while future assessments can make use of better information availability.

2. Small scale studies are needed to complement high level regional sea studies We demonstrated assessments that are high level, at broad ecological (regional sea) scales (ODEMM, MECSA), as well as more local (AQUACROSS, MCES). However, both these types of studies are underpinned by knowledge found from studies on specific habitats, species and ecosystem services, and how people use them. We continue to need these studies to improve understanding and confidence in ecosystem service assessments.

3. Ecosystem service assessments are not equivalent to ecosystem assessments Good ecosystem state does not always equal good capacity to supply services. Good service capacity may be satisfied by a broad habitat or group of taxa supplying it, for example in the whale watching example given above. But within this broad taxa group, several species may be failing their ecological assessments and be vulnerable. Ecosystem service assessments do not replace assessments of biodiversity and ecosystem condition-it is essential that these are seen as complementary.

4. Consider all of the contributions of nature to human wellbeing

There are a number of ecosystem service typologies that can be used today. Although each have their critics, typologies like CICES (v5.1), TEEB and that used in the IPBES (International Panel on biodiversity and Ecosystem Services, (IPBES 2019), which include services that cannot be given a monetary or market value (see discussion on FEGS, DeWitt et al. (2020)), have a broad and encompassing set of ecosystem services that recognises all of the ways that nature contributes to our wellbeing. It is important to recognise services even where they cannot be given a market value, because ultimately, they are contributing to the long-term sustainability of society. It is possible to measure changes to these contributions by using a supply-side approach demonstrated here (e.g. MECSA, MCES), rather than a demand side approach.

5. Establish who are the beneficiaries of ecosystem services

In order to recognise all the contributions of nature to human wellbeing (see 4 above) and to understand how the marine ecosystem contributes to our wellbeing, we need to explicitly identify all of the beneficiaries of coastal and 
marine ecosystem services and how these benefits are perceived. This would help to establish how services are 'final' (sensu FEGS, see DeWitt et al. (2020)) and to establish how best we might measure specific contributions to different parts of society. This may not always be through measuring an economic value, and different, complementary approaches may need to be used side by side to fully capture how nature contributes to human wellbeing.

6. Need for adaptive response to ecosystem service assessment

Ecosystem services are embedded in the current social and ecological context. As this changes, ecosystem service assessments also need to change to keep up. These assessments can inform management about the need to change and adapt in response to changing ecosystem service supply or demand. Furthermore, as mentioned above, a critical point in the decision-making process is to decide who will win and who will lose over time and space. Therefore, adaptive responses are crucial.

7. Link human activities and pressures to ecosystem service supply

Increasing activities and pressures in the marine environment, alongside global climate change, requires urgent assessment of how these activities and pressures are affecting ecosystem service supply and what this will mean for long-term sustainability. The ODEMM approach described above demonstrates how tradeoffs can be explored for different management options, whilst the MCES vulnerability index allows prioritisation of the most vulnerable or most important habitats needed for service supply. These can help to consider where human activities will impact service supply, and where management can act to be most effective, efficient and equitable.

\section{$4.2 \quad$ Next Steps}

The demand side of ecosystem services is socio-economically driven, while the supply side is dependent on ecosystems capacity to provide the required ecosystem services underpinning maritime activities. Europe's Biodiversity Strategy, aims to conserve and restore the supply side of ecosystem services, by halting biodiversity loss and deterioration of services by 2020 (EC 2011). On the other hand, Climate change strategies in the EU are aiming to significantly cut greenhouse gas emissions reaching net zero by 2050 (EC 2018). This will be achieved, at least partly, by increasing the share of renewable energy, including offshore energy. The Blue Growth strategy brings the supply and demand sides together for marine and coastal environments. It aims at supporting an effective implementation of maritime, marine and coastal-related policies, and at "realising the potential of our seas and oceans for jobs and growth" following the principles of conservation and of sustainable development (EC 2012). The strategy also foresees approaches to restore marine and coastal habitats, biodiversity and ecosystem services, being in line with the United Nations SDGs for 2030. 
Therefore, the operationalization of any of these strategies requires balanced trade-offs between economic, social and environmental aspects supported by coastal and marine ecosystem services (Lillebø et al. 2017). To this end, Ecosystem-Based Management incorporating adaptive management is likely to have a critical role (e.g. Lillebø et al. 2020).

Balancing the demands we put on our ecosystems, with what they can sustainably supply, is the challenge of EBM. Ecosystem service assessments are one tool that can help us to do this, by allowing recognition of all the ways that the ecosystem contributes to human wellbeing and all the ways that human activities can impact the ecosystem and the supply of services. While the original ethos of ecosystem services was based in conservation (Ehrlich and Mooney 1983), it is clear that ecosystem service assessments alone do not replace nature conservation, in particular when individual services of interest are assessed, as opposed to multiple ecosystem services (MA 2005; Culhane et al. 2018; Teixeira et al. 2019).

Using the ecosystem service approach to benefit EBM is still challenging. The challenges lie in our knowledge and understanding of how the ecosystem works, in our understanding of human behaviour and the demands of society and in the resources that we have available, such as data or the means to collect data. Nevertheless, we have presented a number of ways showing that ecosystem service assessments can be integrated into EBM decisions. These assessments draw on different approaches in data-limited situations, including expert judgement and stakeholder knowledge, policy information, as well as, detailed habitat mapping or spatially explicit modelling techniques. These are all ways that can be used to achieve a key tenet of EBM, namely that it allows decision makers and stakeholders to see how ecosystem integrity can affect human well-being, thus allowing more balanced actions to be taken.

Acknowledgements ODEMM (EU FP7 Programme 'Options for Delivering Ecosystem Based Marine Management' (ODEMM); Grant number 244273). AQUACROSS (Grant Agreement no. 642317) collaborative research project was supported by the European Commission under the Horizon 2020 Programme for Research, Technological Development and Demonstration. MCES research project was supported by Calouste Gulbenkian Foundation, Portugal, in the context of the 'Gulbenkian Oceans' Initiative. Thanks, are also due to the Portuguese Foundation for Science and Technology (FCT) for the financial support to CESAM (UID/AMB/50017/2019). MECSA was produced under an European Topic Centre grant agreement (Negotiated Procedure EEA/NSV/14/ 002) with the European Environment Agency (EEA). Opinions expressed are those of the authors and do not necessarily reflect the official opinion of the EEA or other European Community bodies and institutions.

\section{References}

Böhnke-Henrichs, A., Baulcomb, C., Koss, R., Hussain, S. S., \& de Groot, R. S. (2013). Typology and indicators of ecosystem services for marine spatial planning and management. Journal of Environmental Management, 130, 135-145. https://doi.org/10.1016/j.jenvman.2013.08.027. 
Burkhard, B., Kroll, F., Nedkov, S., \& Müller, F. (2012). Mapping ecosystem service supply, demand and budgets. Ecological Indicators, 21, 17-29. https://doi.org/10.1016/j.ecolind.2011. 06.019 .

Cabral, P., Levrel, H., Schoenn, J., Thiébaut, E., Le Mao, P., Mongruel, R., et al. (2015). Marine habitats ecosystem service potential: A vulnerability approach in the Normand-Breton (Saint Malo) Gulf, France. Ecosystem Services, 16, 306-318. https://doi.org/10.1016/j.ecoser.2014.09. 007.

Christianen, M. J. A., van Belzen, J., Herman, P. M. J., van Katwijk, M. M., Lamers, L. P. M., van Leent, P. J. M., et al. (2013). Low-canopy seagrass beds still provide important coastal protection services. PLoS One, 8(5), e62413-e62413. https://doi.org/10.1371/journal.pone. 0062413.

Costanza, R., d'Arge, R., de Groot, R., Farber, S., Grasso, M., Hannon, B., et al. (1997). The value of the world's ecosystem services and natural capital. Nature, 387(6630), 253-260. https://doi. org/10.1038/387253a0.

Culhane, F. E., Frid, C. L. J., Royo-Gelabert, E., White, L. J., \& Robinson, L. A. (2018). Linking marine ecosystems with the services they supply: What are the relevant service providing units? Ecological Applications, 28(7), 1740-1751. https://doi.org/10.1002/eap.1779.

Culhane, F., Frid, C. L. J., Royo-Gelabert, E., \& Robinson, L. A. (2019a). EU policy-based assessment of the capacity of marine ecosystems to supply ecosystem services. ETC/ICM Technical Report 2/2019: European Topic Centre on Inland, Coastal and Marine Waters, 269p.

Culhane, F., Teixeira, H., Nogueira, A. J. A., Borgwardt, F., Trauner, D., Lilleb $\varnothing$, A., et al. (2019b). Risk to the supply of ecosystem services across aquatic ecosystems. Science of the Total Environment, 660, 611-621. https://doi.org/10.1016/j.scitotenv.2018.12.346.

Culhane, F., Frid, C. L. J., Royo-Gelabert, E., Piet, G., White, L. J., \& Robinson, L. A. (2020). Assessing the capacity of European regional seas to supply ecosystem services using marine status assessments. Ocean and Coastal Management, 190, 105154

DeWitt, T. H., Berry, W. J., Canfield, T. J., Fulford, R. S., Harwell, M. C., Hoffman, J. C., Johnston, J. M., Newcomer-Johnson, T. A., Ringold, P. L., Russel, M. J., Sharpe, L. A., \& Yee, S. J. H. (2020). The final ecosystem goods and services (FEGS) approach: A beneficiarycentric method to support ecosystem-based management. In T. O'Higgins, M. Lago and \& T. H. DeWitt (Eds.), Ecosystem-based management, ecosystem services and aquatic biodiversity: Theory, tools and applications (pp. 127-148). Amsterdam: Springer.

EC. (2011). Communication from the commission to the European parliament, the council, the economic and social committee and the committee of the regions. Our life insurance, our natural capital: An EU biodiversity strategy to 2020, Brussels, 3.5.2011 COM (2011) 244 Final, 17p.

EC. (2012). Communication from the commission to the European Parliament, the Council, the European Economic and Social Committee and the Committee of the Regions. Blue Growth opportunities for marine and maritime sustainable growth. Brussels, 13.9.2012, COM (2012) 494 final.

EC. (2018). Communication from the commission to the European Parliament, the European Council, the Council, the European Economic and Social Committee, the Committee of the Regions and the European Investment Bank. A Clean Planet for all. A European strategic longterm vision for a prosperous, modern, competitive and climate neutral economy. Brussels, 28.11.2018. COM(2018) 773 final.

EEA. (2015). State of Europe's Seas. EEA Report No 2/2015. Copenhagen, Denmark: European Environment Agency.

Ehrlich, P. R., \& Mooney, H. A. (1983). Extinction, substitution, and ecosystem services. Bioscience, 33(4), 248-254. https://doi.org/10.2307/1309037.

Elejabeitia, C., Urquiola, E., Verborgh, P., \& de Stephanis, R. (2012). Towards a sustainable whalewatching industry in the Mediterranean Sea. In L. M. Rosalino, A. Silva, \& A. Abreu (Eds.), New trends towards Mediterranean tourism sustainability. Nova Science Publishers.

Elliott, M., \& O'Higgins, T.G. (2020). From the DPSIR, the D(A)PSI(W)R(M) emerges... a butterfly-'protecting the natural stuff and delivering the human stuff' In T. O'Higgins, M. 
Lago, \& T. H. DeWitt (Eds.), Ecosystem-based management, ecosystem services and aquatic biodiversity: Theory, tools and applications (pp. 61-86). Amsterdam: Springer.

Fisher, B., Turner, R. K., \& Morling, P. (2009). Defining and classifying ecosystem services for decision making. Ecological Economics, 68(3), 643-653. https://doi.org/10.1016/j.ecolecon. 2008.09.014.

Flood, S., O'Higgins, T. G. and Lago, M. (2020). The promise and pitfalls of ecosystem services classification and valuation. In T. O'Higgins, M. Lago, \& T. H. DeWitt (Eds.), Ecosystem-based management, ecosystem services and aquatic biodiverstiy: Theory, tools and practice (pp. 87-104). Amsterdam: Springer.

Fulford, R. S., Heymans, S. J. J., \& Wu, W. (2020). Mathematical modelling for ecosystem-based management (EBM) and ecosystem goods and services (EGS) assessment. In T. O'Higgins, M. Lago, \& T. H. DeWitt (Eds.), Ecosystem-based management, ecosystem services and aquatic biodiversity: Theory, tools and applications (pp. 275-290). Amsterdam: Springer.

Gómez, C., Delacámara, G., Arévalo-Torres, J., Barbière, J., Barbosa, A., Boteler, B., et al. (2016). The AQUACROSS innovative concept-deliverable 3.1.

Gómez, C., Delacámara, G., Jähnig, S., Langhans, S. D., Domisch, S., Hermoso, V., et al. (2017). Developing the AQUACROSS assessment framework deliverable 3.2.

Haines-Young, R., \& Potschin, M. (2013). Common International Classification of Ecosystem Services (CICES): Consultation on version 4, August-December 2012. EEA Framework Contract No EEA/IEA/09/003.

IPBES. (2019). Summary for policymakers of the global assessment report on biodiversity and ecosystem services of the intergovernmental science-policy platform on biodiversity and ecosystem services. Bonn, Germany: IPBES Secretariat.

IUCN-ACCOBAMS. (2016). Assessment of whale watching activities in the Gibraltar Strait. By Cazalla, E., Casado, J., Catala, T., Tilot, V., Bernal, C. p. 66.

Jumin, R., Binson, A., McGowan, J., Magupin, S., Beger, M., Brown, C. J., et al. (2018). From Marxan to management: Ocean zoning with stakeholders for Tun Mustapha Park in Sabah, Malaysia. Oryx, 52(4), 775-786. https://doi.org/10.1017/S0030605316001514.

King, S. E., \& Lester, J. N. (1995). The value of salt marsh as a sea defence. Marine Pollution Bulletin, 30(3), 180-189. https://doi.org/10.1016/0025-326X(94)00173-7.

Lewis, N. S., Marois, D. E., Littles, C. J., \& Fulford, R. S. (2020). Projecting changes to coastal and estuarine ecosystem goods and services-models and tools. In T. O’Higgins, M. Lago, \& T. H. DeWitt (Eds.), Ecosystem-based management, ecosystem services and aquatic biodiversity: Theory, tools and applications (pp. 235-254). Amsterdam: Springer.

Lillebø, A. I., Pita, C., Garcia Rodrigues, J., Ramos, S., \& Villasante, S. (2017). How can marine ecosystem services support the Blue Growth agenda? Marine Policy, 81, 132-142. https://doi. org/10.1016/j.marpol.2017.03.008.

Lillebø, A. I., Teixeira, H., Morgado, M., Genua-Olmedo, A., Nogueira, A., Delacámara, G., et al. (2018). Case study 5 report: Improving integrated management of Natura 2000 sites in the Ria de Aveiro Natura 2000 site, from catchment to coast, Portugal. Deliverable 9.2, European Union's Horizon 2020 Framework Programme for Research and Innovation Grant Agreement No. 642317. Retrieved from https://aquacross.eu.

Lillebø, A. I., Teixeira, H., Morgado, M., Martínez-López, J., Marhubi, A., Delacámara, G., et al. (2019). Ecosystem-based management planning across aquatic realms at the Ria de Aveiro Natura 2000 territory. Science of the Total Environment, 650, 1898-1912. https://doi.org/10. 1016/j.scitotenv.2018.09.317.

Lillebø, A. I., Teixeira, H., Martinez-Lopez, J., Genua-Olmedo, A., Marhubi, A., Delacámara, G., et al. (2020). Mitigating negative unintended impacts on biodiversity in the Natura 2000 Vouga estuary (Ria de Aveiro, Portugal). In T. O’Higgins, M. Lago, \& T. H. DeWitt (Eds.), Ecosystembased management, ecosystem services and aquatic biodiversity: Theory, tools and applications. (pp. 461-498). Amsterdam: Springer. 
MA. (2005). Millennium ecosystem assessment. Washington, DC.

Maes, J., Teller, A., Erhard, M., Liquete, C., Braat, L., Berry, P., et al. (2013). Mapping and assessment of ecosystems and their services. An analytical framework for ecosystem assessments under action 5 of the EU biodiversity strategy to 2020. Luxembourg.

Maes, J., Liquete, C., Teller, A., Erhard, M., Paracchini, M. L., Barredo, J. I., et al. (2016). An indicator framework for assessing ecosystem services in support of the EU biodiversity strategy to 2020. Ecosystem Services, 17, 14-23. https://doi.org/10.1016/j.ecoser.2015.10.023.

Martínez-López, J., Teixeira, H., Morgado, M., Almagro, M., Sousa, A. I., Villa, F., et al. (2019). Participatory coastal management through elicitation of ecosystem service preferences and modelling driven by 'coastal squeeze'. Science of the Total Environment, 652, 1113-1128. https://doi.org/10.1016/j.scitotenv.2018.10.309.

Mauri, M., Elli, T., Caviglia, G., Uboldi, G., \& Azzi, M. (2017). RAWGraphs: A visualisation platform to create open outputs. In Proceedings of the 12th biannual conference on Italian SIGCHI Chapter. ACM, p. 28.

Nogueira, A. (2018). AquaLinks Tool. Zenodo Dataset. https://doi.org/10.5281/zenodo.1101159.

Piet, G., Delacámara, G., Kraan, M., Rockman, C., \& Lago, M. (2020). Advancing aquatic ecosystem-based management with full consideration of the social-ecological system. In T. O’Higgins, M. Lago, \& T. H. DeWitt (Eds.), Ecosystem-based management, ecosystem services and aquatic biodiversity: Theory, tools and applications (pp. 17-38). Amsterdam: Springer.

Potschin, M. B., \& Haines-Young, R. H. (2011). Ecosystem services: Exploring a geographical perspective. Progress in Physical Geography: Earth and Environment, 35(5), 575-594. https:// doi.org/10.1177/0309133311423172.

Robinson, L., \& Culhane, F. (2020). Linkage frameworks: An exploration tool for complex systems. In T. O'Higgins, M. Lago, \& T. H. DeWitt (Eds.), Ecosystem-based management, ecosystem services and aquatic biodiversity: Theory, tools and applications (pp. 213-234). Amsterdam: Springer.

Robinson, L. A., Culhane, F. E., Baulcomb, C., Bloomfield, H., Boehnke-Henrichs, A., Breen, P., et al. (2014). Towards delivering ecosystem-based marine management: The ODEMM approach. Deliverable 17, EC FP7 Project (244273) 'Options for Delivering Ecosystem-based Marine Management'. University of Liverpool. ISBN: 978-0-906370-89-6: 96p.

Ryan, C., Bolin, V., Shirra, L., Garrard, P., Putsey, J., Vines, J., et al. (2018). The development and value of whale-watch tourism in the west of Scotland. Tourism in Marine Environments, 13(1), $17-24$

TEEB. (2010). The economics of ecosystems and biodiversity (TEEB). Retrieved from http://www. teebweb.org/.

Teixeira, H., Lillebø, A., Culhane, F., Robinson, L., Trauner, D., Borgwardt, F., et al. (2018). Assessment of causalities, highlighting results from the application of meta-ecosystem analysis in the case studies-Synthesis report. Deliverable 5.2, European Union's Horizon 2020 Framework Programme for Research and Innovation Grant Agreement No. 642317. Retrieved from https://aquacross.eu.

Teixeira, H., Lillebø, A. I., Culhane, F., Robinson, L., Trauner, D., Borgwardt, F., et al. (2019). Linking biodiversity to ecosystem services supply: Patterns across aquatic ecosystems. Science of the Total Environment, 657, 517-534. https://doi.org/10.1016/j.scitotenv.2018.11.440.

UNEP. (2011). Taking steps toward marine and coastal ecosystem-based management - An introductory guide, by Agardy, T., Davis, T., Sherwood, K., Vestergaard, O. UNEP Regional Seas Reports and Studies No. 189. ISBN: 9789280731736.

van Lier, J. R., Wilson, S. K., Depczynski, M., Wenger, L. N., \& Fulton, C. J. (2018). Habitat connectivity and complexity underpin fish community structure across a seascape of tropical macroalgae meadows. Landscape Ecology, 33(8), 1287-1300. https://doi.org/10.1007/s10980018-0682-4. 
Watts, M. E., Ball, I. R., Stewart, R. S., Klein, C. J., Wilson, K., Steinback, C., et al. (2009). Marxan with zones: Software for optimal conservation based land- and sea-use zoning. Environmental Modelling and Software, 24(12), 1513-1521. https://doi.org/10.1016/j.envsoft.2009.06.005.

Willaert, T., García-Alegre, A., Queiroga, H., Cunha-e-Sá, M. A., \& Lillebø, A. I. (2019). Measuring vulnerability of marine and coastal habitats' potential to deliver ecosystem services: Complex Atlantic region as case study (original research). Frontiers in Marine Science, 6(199). https://doi.org/10.3389/fmars.2019.00199.

Willcock, S., Martínez-López, J., Hooftman, D. A. P., Bagstad, K. J., Balbi, S., Marzo, A., et al. (2018). Machine learning for ecosystem services. Ecosystem Services, 33, 165-174. https://doi. org/10.1016/j.ecoser.2018.04.004.

Open Access This chapter is licensed under the terms of the Creative Commons Attribution 4.0 International License (http://creativecommons.org/licenses/by/4.0/), which permits use, sharing, adaptation, distribution and reproduction in any medium or format, as long as you give appropriate credit to the original author(s) and the source, provide a link to the Creative Commons licence and indicate if changes were made.

The images or other third party material in this chapter are included in the chapter's Creative Commons licence, unless indicated otherwise in a credit line to the material. If material is not included in the chapter's Creative Commons licence and your intended use is not permitted by statutory regulation or exceeds the permitted use, you will need to obtain permission directly from the copyright holder. 